Article

\title{
Three-Dimensional Honeycomb-Like Porous Carbon with Both Interconnected Hierarchical Porosity and Nitrogen Self-Doping from Cotton Seed Husk for Supercapacitor Electrode
}

\author{
Hui Chen ${ }^{1}$, Gang Wang ${ }^{1,2,3}$, Long Chen ${ }^{1}$, Bin Dai ${ }^{1}$ and Feng Yu ${ }^{1, *(D)}$ \\ 1 Key Laboratory for Green Processing of Chemical Engineering of Xinjiang Bingtuan, School of Chemistry \\ and Chemical Engineering, Shihezi University, Shihezi 832003, China; huichen09@sina.com (H.C.); \\ wanggang@shzu.edu.cn (G.W.); chenlong323@shzu.edu.cn (L.C.); db_tea@shzu.edu.cn (B.D.) \\ 2 Key Laboratory of Materials-Oriented Chemical Engineering of Xinjiang Uygur Autonomous Region, \\ Shihezi 832003, China \\ 3 Engineering Research Center of Materials-Oriented Chemical Engineering of Xinjiang Production and \\ Construction Corps, Shihezi 832003, China \\ * Correspondence: yufeng05@mail.ipc.ac.cn; Tel.: +86-993-205-7272; Fax: +86-993-205-7270
}

Received: 3 May 2018; Accepted: 6 June 2018; Published: 8 June 2018

\begin{abstract}
Hierarchical porous structures with surface nitrogen-doped porous carbon are current research topics of interest for high performance supercapacitor electrode materials. Herein, a three-dimensional (3D) honeycomb-like porous carbon with interconnected hierarchical porosity and nitrogen self-doping was synthesized by simple and cost-efficient one-step $\mathrm{KOH}$ activation from waste cottonseed husk (a-CSHs). The obtained a-CSHs possessed hierarchical micro-, meso-, and macro-pores, a high specific surface area of $1694.1 \mathrm{~m}^{2} / \mathrm{g}$, 3D architecture, and abundant self $\mathrm{N}$-doping. Owing to these distinct features, a-CSHs delivered high specific capacitances of $238 \mathrm{~F} / \mathrm{g}$ and $200 \mathrm{~F} / \mathrm{g}$ at current densities of $0.5 \mathrm{~A} / \mathrm{g}$ and $20 \mathrm{~A} / \mathrm{g}$, respectively, in a $6 \mathrm{~mol} / \mathrm{L} \mathrm{KOH}$ electrolyte, demonstrating good capacitance retention of $84 \%$. The assembled a-CSHs-based symmetric supercapacitor also displayed high specific capacitance of $52 \mathrm{~F} / \mathrm{g}$ at $0.5 \mathrm{~A} / \mathrm{g}$, with an energy density of $10.4 \mathrm{Wh} / \mathrm{Kg}$ at $300 \mathrm{~W} / \mathrm{Kg}$, and $91 \%$ capacitance retention after 5000 cycles at $10 \mathrm{~A} / \mathrm{g}$.
\end{abstract}

Keywords: nitrogen doping; hierarchical structure; porous carbon; three-dimensional architecture; cotton seed husk; supercapacitor; sustainable biomass

\section{Introduction}

Supercapacitors are receiving extensive attention worldwide on account of their fast charge/discharge rates, higher power densities, and excellent cycling stabilities, which are superior to other energy storage devices [1-3]. The energy storage mechanisms of supercapacitors are mainly based on electrical double layer capacitance (EDLC), which occurs at the electrode/electrolyte interface [4,5], and pseudo-capacitors with reversible Faradic redox reaction [6]. Their relatively simple energy storage mechanisms and fast charge/discharge traits make supercapacitors the most promising energy storage devices [7-9]. However, the energy that is stored in a supercapacitor is lower than that in batteries. This has inspired research focused on increasing the supercapacitor's energy density, while maintaining high power density [10].

Recently, studies have been conducted to produce porous carbon-based electrode materials, mainly focusing on porous structures [11,12]. In general, specific surface area (SSA) is the most important feature that influences the electrochemical performances of porous carbon materials $[1,13,14]$. 
High SSA benefits include good energy storage, especially for high rate performance. On the other hand, hierarchical pore size distribution accelerates the ion transfer from the electrolyte to electrode surface [15]. Typically, macro- and meso-pores provide space for electrolyte storage, thereby reducing the ion diffusion distance and ion diffusion resistance, which is conducive to better capacitive performance [16-18]. Additionally, three-dimensional (3D) frameworks are capable of supplying stable frame structures, inter-connected pore networks, and are further conducive to ion transfer $[18,19]$. However, in order to obtain above 3D hierarchical porous carbons (3D-HPCs), it is necessary to add a certain amount of hard templates or soft templates in most of the previously reported works [20-22]. Consequently, the synthesis of 3D-HPCs is limited by its complex, time-consuming, and costly processes.

Surface functional groups also play an important role in energy storage. Nitrogen doping is the most widely studied [23-25]. Generally, a proper amount of nitrogen doping promotes the electrochemical capacitance, by improving the wettability of the porous carbon electrode material, thus bringing about the properties of pseudo-capacitance [26-29]. Nitrogen-doped carbon is achieved by the pyrolysis of nitrogen-enriched polymer precursors and subsequent physicochemical activation, to obtain a nitrogen-doped carbon material. The process is expensive, time-consuming, and endangers our environment $[30,31]$. On the other hand, through the post-treatment of porous carbon with organic and inorganic nitrogen sources [32], urea [33,34] and ammonia [23,35], it is possible to obtain nitrogen-doped porous carbon. However, the resulting carbon material rarely has the previously mentioned 3D hierarchical structure. The traditional synthesis of 3D hierarchical nitrogen-doped porous carbon (3D-HNPCs) materials is limited to this complex, time-consuming, and costly process. Therefore, transforming sustainable raw materials into highly-performing 3D-HNPC materials, through a simple preparation method, is required.

In this work, we have successfully prepared a 3D hierarchical structure of nitrogen self-doped porous carbon from waste cottonseed husks (CSHs), for high performance supercapacitor electrode materials, using one-step $\mathrm{KOH}$ activation. After carbonization and activation, the obtained a-CSHs will have the following features. Firstly, it has a 3D architecture that is associated with hierarchical micro-, meso-, and macro-pores, a high specific surface area of $1694.1 \mathrm{~m}^{2} / \mathrm{g}$, and a moderate pore volume of $0.87 \mathrm{~cm}^{3} / \mathrm{g}$. Secondly, the obtained a-CSHs also contain a moderate nitrogen content of 2.56 atom \%, which is as a result of the protein content in the raw materials. Thirdly, the synthesis process is also simple and convenient for large-scale industrial production. The formation of a 3D hierarchical structure is based on the fact that $\mathrm{KOH}$ acts both as hard template to form 3D structures and as an activator to produce affluent micropores on the surface of the carbon material. Finally, cotton is an important agricultural crop in China, with an annual production of 1.5 million tons [36]. The Xinjiang Production and Construction Corps occupies up to $70 \%$ of the total production. Cottonseed is mainly used to extract cottonseed oil, thereby generating a large amount of sustainable raw material. On the basis of the above advantages, a-CSHs provide high performed high supercapacitor performances in three- and two-electrode systems.

\section{Materials and Methods}

\subsection{Sample Preparation}

The preparation of nitrogen self-doped three-dimensional (3D) honeycomb-like porous carbon was synthesized by one-step $\mathrm{KOH}$ activation. The specific preparation steps were as follows: Cottonseed husk (CSH) was fully washed with deionized water to remove ash and other impurities, and then dried at $100{ }^{\circ} \mathrm{C}$ for $10 \mathrm{~h}$. It was further crushed to form a powder and passed through a 200 mesh sieve for further use. Subsequently, the CSH powder was vigorously stirred with an aqueous $\mathrm{KOH}$ solution at a mass ratio of $\mathrm{KOH} / \mathrm{CSH}$ powder $=1$, and then dried at $80^{\circ} \mathrm{C}$. The mixture was then activated in a tube furnace under an Ar atmosphere at $600{ }^{\circ} \mathrm{C}, 700{ }^{\circ} \mathrm{C}$, or $800{ }^{\circ} \mathrm{C}$ for $1 \mathrm{~h}$ with a heating rate of $5{ }^{\circ} \mathrm{C} / \mathrm{min}$. The obtained product was washed with $10 \% v / v \mathrm{HCl}$ to remove the metal 
impurities, was washed with deionized water until the $\mathrm{pH}$ of the filtrate was 7.0, and was dried at $80{ }^{\circ} \mathrm{C}$ for $10 \mathrm{~h}$. The obtained samples were denoted a-CSH-x, where $\mathrm{x}$ represented the activation temperature.

\subsection{Material Characterization}

Scanning electron microscopy (SEM) surveys were examined with a Hitachi SU8010 microscope (Tokyo, Japan). Transmission electron microscopy (TEM) and energy dispersive X-ray spectroscopy (EDS) were analyzed by a field emission Tecnai G2 F20 electron (Hillsboro, OR, USA) microscope. X-ray diffraction (XRD) measurements were carried out on a Bruker D8 Advance X-ray diffractometer with $\mathrm{Cu}-\mathrm{K} \alpha$ radiation (Karlsruhe, Germany). Specific surface areas of the samples were calculated using the Brunauer-Emmett-Teller (BET) method (Micromeritics ASAP 2020 BET apparatus, Atlanta, GA, USA). The pore size distribution (PSD) curves were derived from the adsorption branch, using a nonlocal density functional theory (NLDFT) model assuming slit pore geometry. The surface chemical compositions were determined using an ESCALAB 250Xi (Thermo Fisher Scientific, USA) X-ray photoelectron spectroscope (XPS). The Raman spectra were collected on a LabRAM HR800 Laser Confocal Micro-Raman Spectroscope (Horiba Jobin Yvon, Franch) with a laser wavelength of $532 \mathrm{~nm}$.

\subsection{Electrochemical Measurements}

The electrochemical properties of the as-prepared samples were tested on a CHI 760E working station with a $6 \mathrm{M} \mathrm{KOH}$ electrolyte. Cyclic voltammetry $(\mathrm{CV})$ tests at different scanning rates and galvanostatic charge/discharge (GCD) curves under varying current densities were used to evaluate the electrochemical performances of the electrode materials. The working electrode was obtained by mixing carbon material $(5 \mathrm{mg})$ with acetylene black $(1 \mathrm{mg})$ and polytetrafluoroethylene $(1 \mu \mathrm{L})$ in absolute ethanol $(1 \mathrm{~mL})$. The mixture was dispersed by ultrasound for $40 \mathrm{~min}$ and the ink-like dispersion that was obtained was transferred to nickel foam $(1 \mathrm{~cm} \times 1 \mathrm{~cm})$ and then vacuum dried at $80{ }^{\circ} \mathrm{C}$ for $10 \mathrm{~h}$. The nickel foam was further pressed on a tablet press at $20 \mathrm{MPa}$ for $1 \mathrm{~min}$ and was immersed in $6 \mathrm{M} \mathrm{KOH}$ for further testing. The loaded mass of each electrode was $5 \mathrm{mg}$. For the three-electrode system, the Pt sheet and Saturated Calomel Electrode (SCE) were utilized as counter electrode and reference electrode, respectively. The specific capacitances of the samples were calculated through discharge curves following Equation (1), as follows:

$$
C=\frac{I \times \Delta t}{m \times \Delta V}
$$

where $C(\mathrm{~F} / \mathrm{g})$ is the specific capacitance, $I(\mathrm{~A})$ is the charge/discharge current, $\Delta t$ (s) is the discharging time, $m(\mathrm{~g})$ is the mass of the working electrode, and $\Delta V(\mathrm{v})$ is the voltage window of the charge/discharge process.

The electrochemical properties of a-CSH-700 were measured with the two electrode system. Two symmetrical electrodes were separated by a cellulose membrane in a $6 \mathrm{M} \mathrm{KOH}$ electrolyte and were assembled in a CR2032 stainless-steel coin cell. The specific capacitance was calculated from the discharge process, according to Equation (1). The energy density and power density of symmetric supercapacitor systems were further calculated by Equations (2) and (3).

$$
\begin{gathered}
E=\frac{1}{2} C_{\mathrm{t}} \Delta V^{2} \times \frac{1}{3.6} \\
P=\frac{E}{\Delta t} \times 3600
\end{gathered}
$$

where $E(\mathrm{Wh} / \mathrm{kg}), P(\mathrm{~W} / \mathrm{kg}), C_{\mathrm{t}}(\mathrm{F} / \mathrm{g}), \Delta V(\mathrm{v})$, and $\Delta t(\mathrm{~h})$ are the specific energy density, specific power density, specific capacitance, and voltage window, respectively, of the symmetrical supercapacitor system. 


\section{Results}

Nitrogen self-doped 3D honeycomb-like porous carbon was prepared through one-step activation from waste cottonseed husk (CSH). Cotton seeds were generally collected for the preparation of cottonseed oil; large amounts of cotton seed husks were not effectively used and were abandoned. Therefore, we recycled them to prepare high-performance biomass-derived electrode materials (Figure 1a,b). The material preparation process is shown in Figure $1 \mathrm{~b}-\mathrm{d}$. Pretreated CSH powder (Figure 1c) was directly stirred with aqueous $\mathrm{KOH}$ solution and dried for carbonization and activation. The temperature for activation was adjusted from $600{ }^{\circ} \mathrm{C}$ to $800{ }^{\circ} \mathrm{C}$, and the carbon that was obtained was washed and dried. The entire preparation process was cost-efficient, simple, and easily achieved the industrialized requirements.

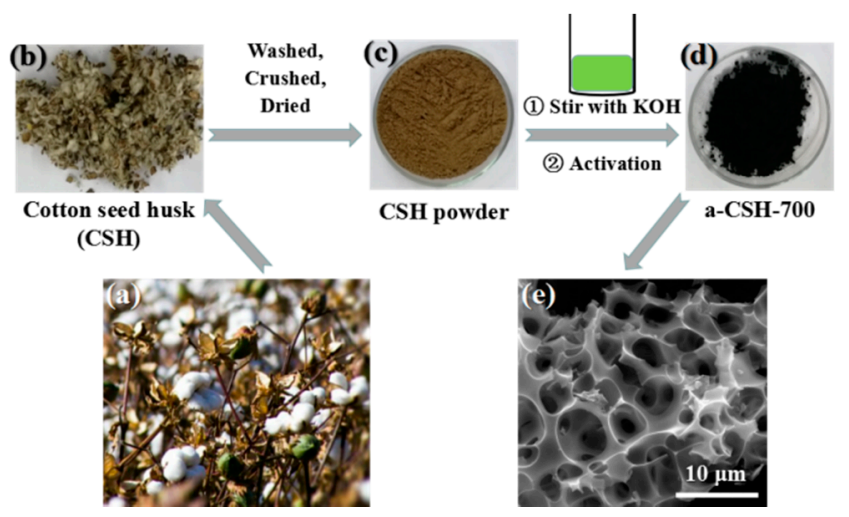

Figure 1. Schematic diagrams for the fabrication of a-CSH-700 and the corresponding scanning electron microscopy (SEM) image. (a) Images of cotton. (b-d) Schematic of the synthesis of a-CSH-700 derived from cottonseed husk, and (e) the corresponding SEM images of a-CSH-700.

Scanning electron microscopy (SEM) images of a-CSH-600, 700, and 800 are shown in Figure 2a-f. The micromorphologies of the obtained samples showed typical 3D inter-connected honeycomb-like microstructures at different pyrolysis temperatures. The chemical composition of the waste cottonseed husk had a certain degree of degradation after stirring and evaporation with an aqueous $\mathrm{KOH}$ solution. Subsequently, the following chemical reaction of $\mathrm{CSH}$ and $\mathrm{KOH}$ during carbonization and activation processes occurred: $6 \mathrm{KOH}+\mathrm{C} \rightarrow 2 \mathrm{~K}+3 \mathrm{H}_{2}+2 \mathrm{~K}_{2} \mathrm{CO}_{3}$, followed by the decomposition of $\mathrm{K}_{2} \mathrm{CO}_{3}$, and the simultaneous generation of $3 \mathrm{D}$ pore structures and graphite sheet-like layer structures $[8,37,38]$. The lateral size of the 3D porous carbon varied in the range $400 \mathrm{~nm}$ to $4 \mu \mathrm{m}$ (Figure $1 \mathrm{~d}-\mathrm{f}$ ). With the increasing pyrolysis temperature, the characteristics of the 3D structure were slightly damaged, which was mainly because the higher temperature was bad for obtaining the 3D structure. The 3D linked carbon skeleton caused the obtained carbon material to exhibit a higher specific surface area. Moreover, this unique 3D structure generated abundant interconnected pore structure that allowed the electrolyte to be stored therein, reducing the distance that the electrolyte travelled on the surface of the electrode material. At the same time, abundant micropores and mesoporous structures existed on the surface of the carbon material (Figure 3a,b). With the help of these multi-level pore structures, it was easy to obtain a high energy storage performance. 

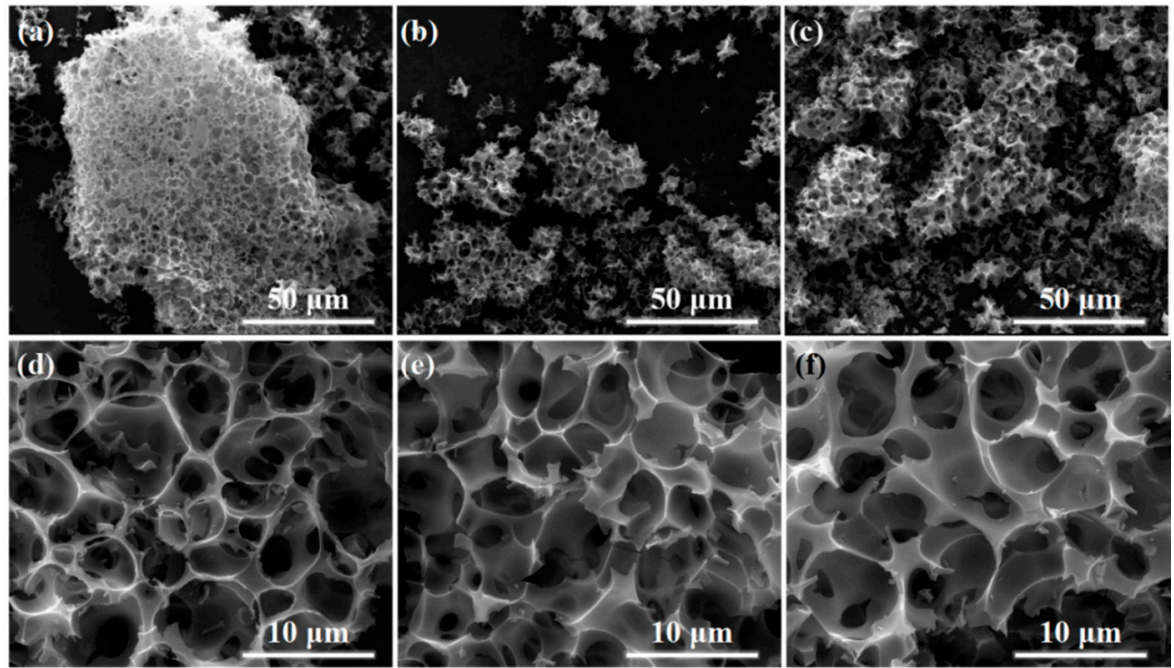

Figure 2. SEM images of (a,d) a-CSH-600, (b,e) a-CSH-700, and (c,f) a-CSH-800.
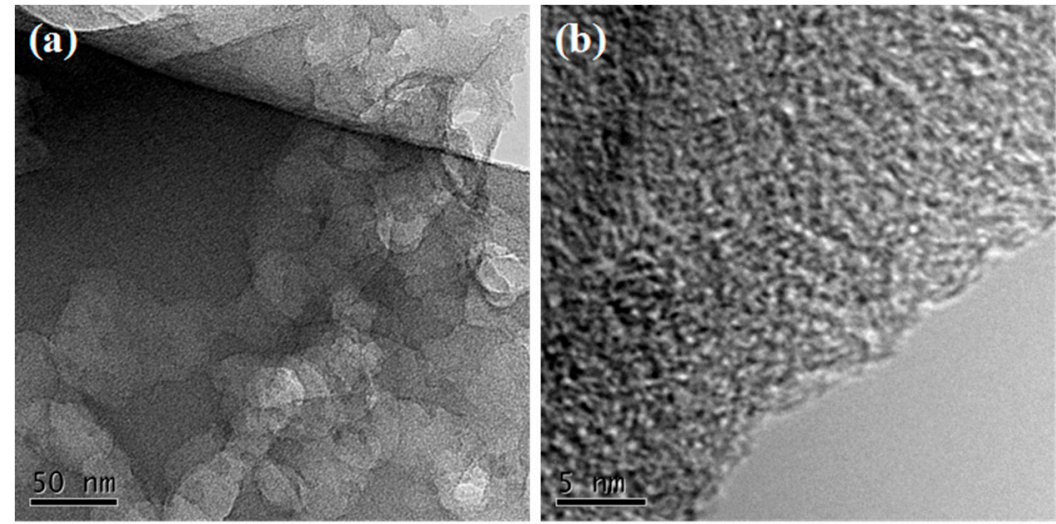

Figure 3. Transmission electron microscopy (TEM) image (a) and high-resolution TEM (HRTEM) image (b) of a-CSH-700

The powder X-ray diffraction (XRD) patterns of as-prepared a-CSHs samples are shown in Figure $4 \mathrm{a}$. There were two distinct peaks at around $2 \theta=22.1^{\circ}$ and $43.5^{\circ}$, which were ascribed to the (002) and (100) reflections of the amorphous graphitic carbon structure. The high intensity values at the low angles indicated high specific surface areas of carbon materials. The obvious peak at $43.5^{\circ}$ revealed a higher degree of interlayer condensation in a-CSHs, which also significantly increased the electrical conductivity. Raman spectroscopy was further used to characterize the a-CSHs samples. As shown in Figure 4b, there were three distinct peaks at $1343 \mathrm{~cm}^{-1}$ (D band), $1590 \mathrm{~cm}^{-1}$ ( $\mathrm{G}$ band), and $2800 \mathrm{~cm}^{-1}$ (2D band). The $\mathrm{D}$ band represented the degree of the defects and disordered $\mathrm{sp}^{3}$ carbon atoms in the sample, and the $\mathrm{G}$ band was in line with graphite $\mathrm{sp}^{2}$ hybridized carbon atoms in the sample. The presence of a 2D peak indicated that there existed an ordered graphite-like structure in the a-CSHs. The intensity ratio of $\mathrm{D}$ band to $\mathrm{G}$ band $\left(\mathrm{I}_{\mathrm{D}} / \mathrm{I}_{\mathrm{G}}\right)$ represented the disorder degree of the samples $[39,40]$. The $\mathrm{I}_{\mathrm{D}} / \mathrm{I}_{\mathrm{G}}$ ratios of a-CSH-600, a-CSH-700, and a-CSH-800 were $0.83,0.84$, and 0.87 , respectively. We confirmed that the chemical reaction became deeper with rise in activation temperature, which promoted the defects and disordered structures in a-CSH-700 and a-CSH-800. 

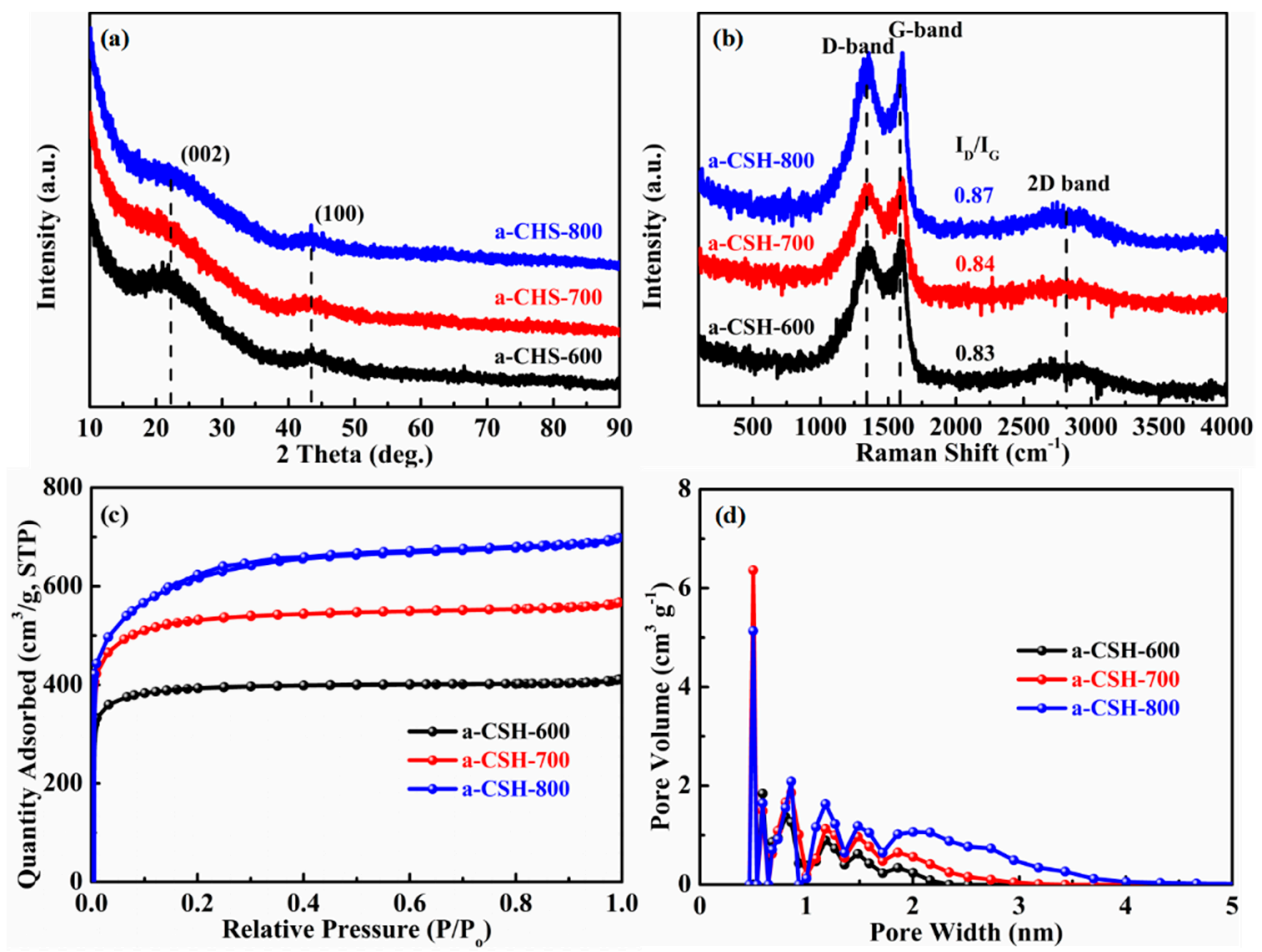

Figure 4. Powder X-ray diffraction (XRD) patterns (a) and Raman spectra (b) of a-CSHs samples. (c) Nitrogen adsorption-desorption isotherms and (d) pore size distributions of a-CSHs.

The nitrogen adsorption/desorption measurements were further used to examine the pore properties of a-CSHs. The nitrogen adsorption-desorption isotherm and pore size distribution curve of a-CSHs are shown in Figure $4 \mathrm{c}, \mathrm{d}$, respectively. It could be seen that all of the a-CSHs samples displayed type I isotherms [41]. With the increase in pyrolysis temperature, the corresponding quantity adsorbed value also increased [42]. This suggested that the specific surface area increased with an increase in the activation temperature. Figure $4 \mathrm{~d}$ displays the pore size distribution isotherms. The dominant pore size distribution was located in the micropores $(0.5-2 \mathrm{~nm})$, and a part in mesopores (2-4 nm). a-CSH-600, a-CSH-700, and a-CSH-800 exhibited hierarchical porous structures, abundant micropores, and profuse mesopores, respectively, which were consistent with the results of the SEM images. Table 1 also summarizes the information on the specific BET surface areas and pore sizes of all of the a-CSHs samples. The specific surface areas of a-CSH-600, a-CSH-700, and a-CSH-800 were determined to be $1257.8,1694.1$, and $2063.0 \mathrm{~m}^{2} / \mathrm{g}$, respectively, while the pore volumes were $0.64,0.87$, and $1.07 \mathrm{~cm}^{3} / \mathrm{g}$, respectively. This showed that the temperature of activation was a dominating factor for the development of pore structure.

Table 1. Pore characteristics of the a-CSHs samples.

\begin{tabular}{cccccc}
\hline Samples & $\mathbf{S}_{\mathbf{B E T}}{ }^{\mathbf{a}}\left(\mathbf{m}^{2} / \mathbf{g}\right)$ & $\mathbf{S}_{\mathbf{m i}}{ }^{\mathbf{b}}\left(\mathbf{m}^{2} / \mathbf{g}\right)$ & $\mathbf{V}_{\text {total }}{ }^{\mathbf{c}}\left(\mathbf{c m}^{\mathbf{3}} / \mathbf{g}\right)$ & $\mathbf{V}_{\text {mid }} \mathbf{b}^{\left(\mathbf{m}^{2} / \mathbf{g}\right)}$ & $\mathbf{D}_{\text {aver }}{ }^{\mathbf{d}}(\mathbf{n m})$ \\
\hline a-CSH-600 & 1257.8 & 1051.0 & 0.64 & 0.51 & 3.95 \\
a-CSH-700 & 1694.1 & 1253.5 & 0.87 & 0.63 & 3.76 \\
a-CSH-800 & 2063.0 & 1080.0 & 1.07 & 0.52 & 2.60 \\
\hline
\end{tabular}

${ }^{a}$ Total surface area calculated using the Brunauer-Emmett-Teller (BET) method; ${ }^{\mathrm{b}}$ Micropore surface area and volume calculated from the $\mathrm{t}$-plot method; ${ }^{\mathrm{c}}$ Total pore volume calculated at $\mathrm{P} / \mathrm{P}_{\mathrm{o}}=0.99 ;{ }^{\mathrm{d}}$ Average pore diameter calculated from the (Barrett-Joyner-Halenda) BJH desorption.

The chemical compositions and surface functional groups of as-prepared a-CSH-600, a-CSH-700, and a-CSH-800 were further characterized by XPS measurements. As shown in the survey spectra 
(Figure 5a), there existed three distinct peak signals corresponding to the $\mathrm{C} 1 \mathrm{~s}$ peak near $286 \mathrm{eV}$, the $\mathrm{N}$ 1s peak near $400 \mathrm{eV}$, and the $\mathrm{O}$ 1s peak near $534 \mathrm{eV}$. Table 2 lists the statistical results of the corresponding elemental contents of the as-prepared carbon materials. The carbon content decreased and the associated oxygen content increased with rise in activation temperature. The nitrogen content of a-CSHs ranged from 1.51 to 2.56 atom \%, the main reason being the complex chemical processes and structure features of these groups at a higher temperature. Figure 6 shows the element mapping images of as-obtained a-CSH-700. The nitrogen was uniformly distributed on the surface of the carbon, and the nitrogen content was 2.62 atom \%.

Figure 5b-d displays high resolution $\mathrm{C} 1 \mathrm{~s}, \mathrm{O} 1 \mathrm{~s}$, and $\mathrm{N}$ 1s spectra of the as-prepared carbon materials. The high resolution C 1s spectrum (Figure 5b) of a-CSHs was resolved into four individual peaks at 284.6, 285.7, 286.7, and $289.2 \mathrm{eV}$, corresponding to $\mathrm{C}=\mathrm{C}, \mathrm{C}-\mathrm{C}, \mathrm{C}-\mathrm{O}$, and $\mathrm{C}=\mathrm{O}$, respectively $[43,44]$. The high-resolution $\mathrm{O} 1 \mathrm{~s}$ spectrum at 530.8, 531.9, 533, and $534.1 \mathrm{eV}$ were associated with $\mathrm{COOH}, \mathrm{O}-\mathrm{C}=\mathrm{O} / \mathrm{N}-\mathrm{C}=\mathrm{O}, \mathrm{C}-\mathrm{O}=\mathrm{C}$, and $\mathrm{C}-\mathrm{OH} / \mathrm{N}-\mathrm{O}-\mathrm{C}$, respectively $[45,46]$. The high-resolution $\mathrm{N}$ 1s spectrum was composed of pyridinic- $\mathrm{N}$ (398.4 eV), pyrolic-N (400.1 eV), quaternary-N (401 eV), and oxidized-N (402.7 eV) [47-49]. These nitrogen and oxygen functional groups enhanced the surface wettabilities of the a-CSHs, and thereby promoting the specific capacitances of the as-prepared carbon materials $[8,50,51]$.

Table 2. Elemental contents of a-CSHs samples from X-ray photoelectron spectroscope (XPS) and EDS.

\begin{tabular}{ccccc}
\hline \multirow{2}{*}{ Samples } & \multicolumn{3}{c}{ Composition (from XPS) } & (from EDX) \\
\cline { 2 - 5 } & $\mathbf{C}$ (atom \%) & O (atom \%) & N (atom \%) & N (atom \%) \\
\hline a-CSH-600 & 90.03 & 8.46 & 1.51 & 1.87 \\
a-CSH-700 & 90.11 & 7.33 & 2.56 & 2.62 \\
a-CSH-800 & 91.19 & 6.37 & 2.44 & 2.86 \\
\hline
\end{tabular}
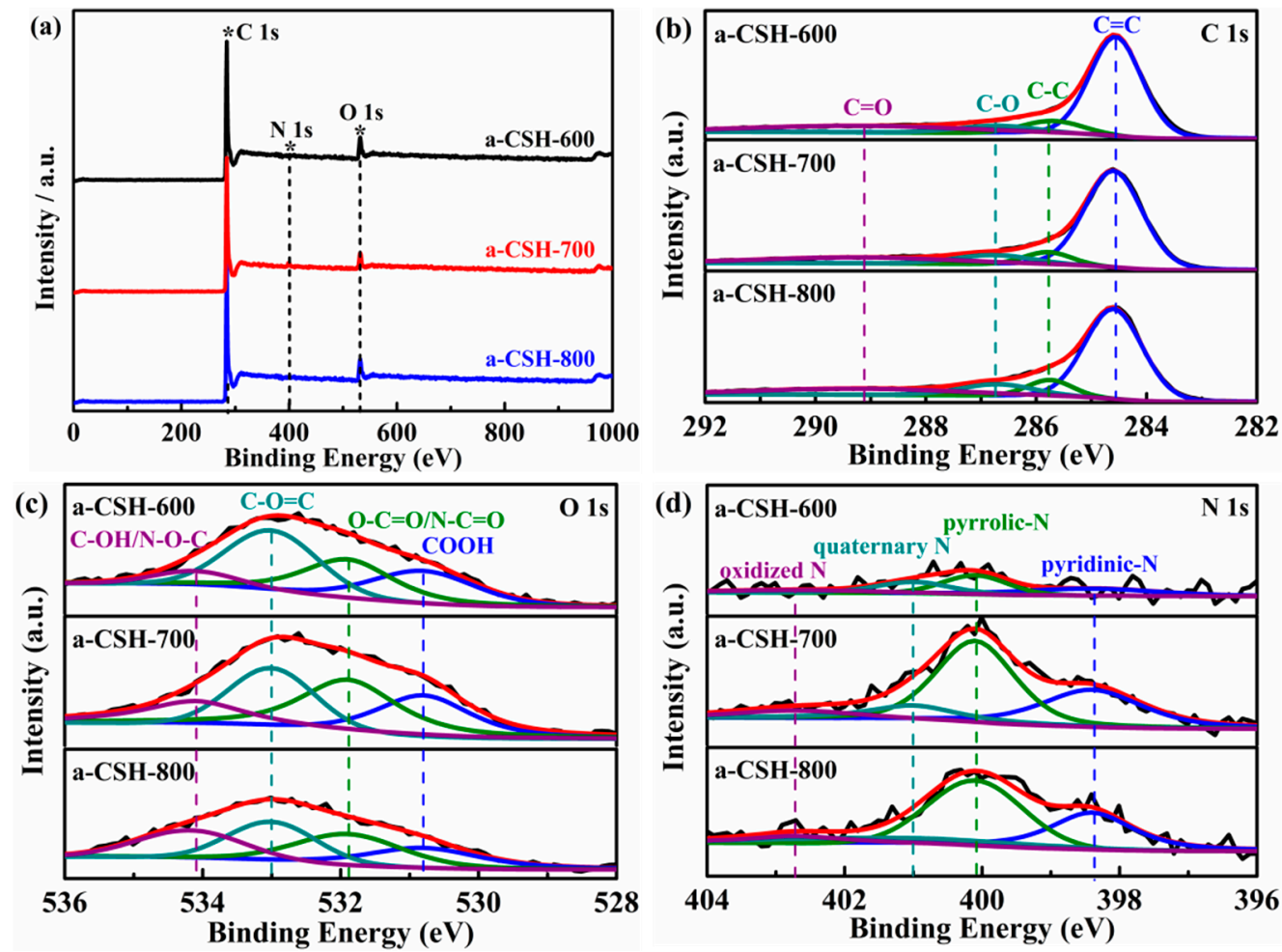

Figure 5. XPS images of the a-CSH-600, a-CSH-700, and a-CSH-800 (a). High-resolution $\mathrm{C}$ 1s (b), $\mathrm{O} 1 \mathrm{~s}(\mathbf{c})$, and $\mathrm{N} 1 \mathrm{~s}(\mathbf{d})$ of the a-CSH-600, a-CSH-700, and a-CSH- 800. 

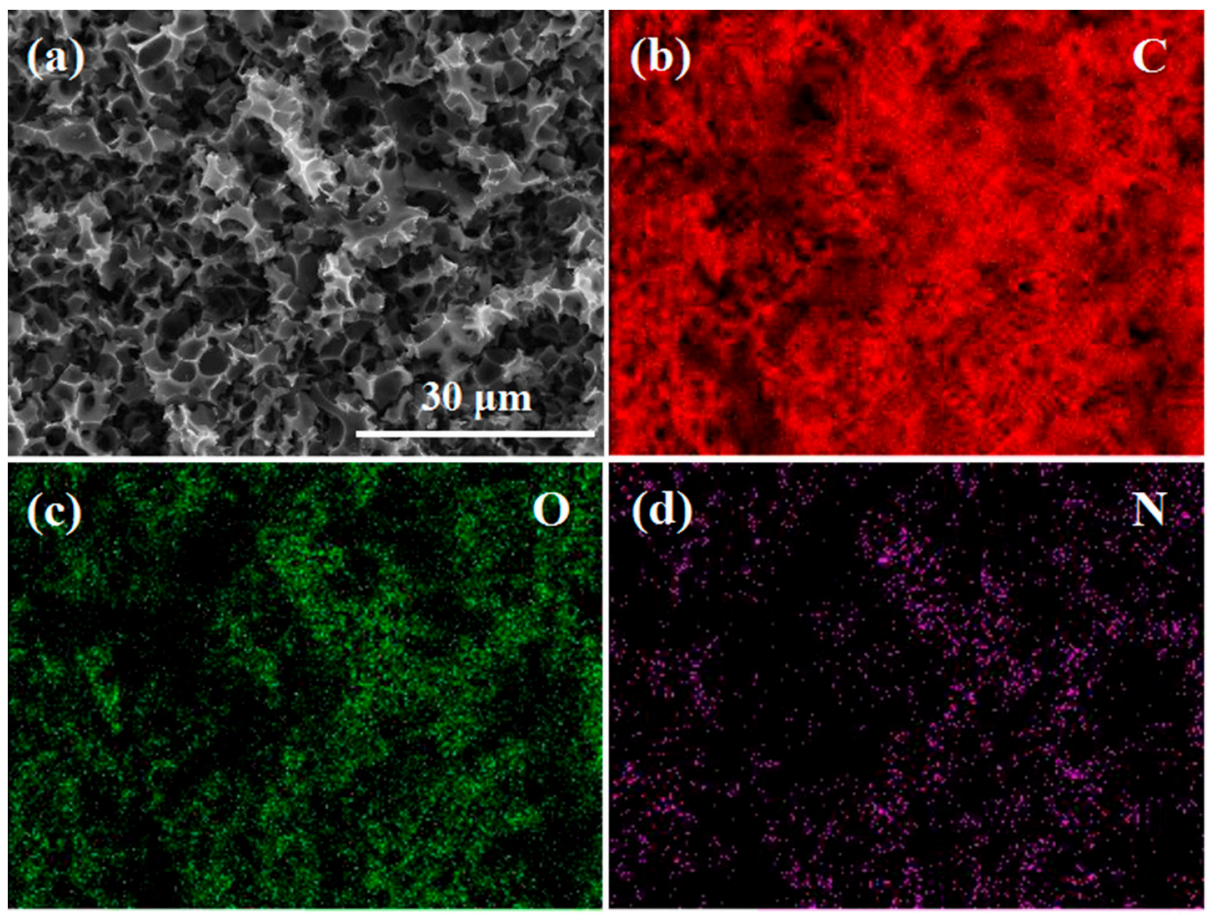

Figure 6. (a) SEM image of a-CSH-700, and elemental mapping images of (b) $\mathrm{C}$, (c) $\mathrm{O}$, and (d) $\mathrm{N}$.

The general standards for designing high performance supercapacitor electrodes were associated with high specific capacitance, good rate capability, and long cycle stability. According to the above conclusions, the a-CSHs derived from one-step synthesis possessed many advantages for supercapacitor electrode materials. The a-CSHs had superior specific surface area for forming ideal electrochemical double layers. The interconnected micropores and mesopores could increase ion transport and the abundant surface nitrogen functional groups improved the wettability and promoted electrical conductivity. The 3D structure provided space for electrolyte storage. These characteristics endowed a-CSHs with a high supercapacitor performance.

The electrochemical performances of the obtained a-CSHs were tested by a three-electrode system in a $6 \mathrm{M} \mathrm{KOH}$ aqueous electrolyte and the $\mathrm{CV}$ curves are shown in Figure 7. The CV curves of a-CSH-600 (Figure 7a), a-CSH-700 (Figure 7b), and a-CSH-800 (Figure 7c) showed typical quasi-rectangular shapes at scan rates from $5 \mathrm{mV} / \mathrm{s}$ to $50 \mathrm{mV} / \mathrm{s}$. This suggested that all of the samples displayed ideal electrochemical double layer capacitances. The CV curves of a-CSH-700 had the largest current responses and areas, suggesting the highest capacitance. Furthermore, galvanostatic charge/discharge (GCD) was further used to assess the electrochemical performance, which is shown in Figure 8. The GCD curves of a-CSH-600 (Figure 8a), a-CSH-700 (Figure 8b), and a-CSH-800 (Figure 8c) showed typical quasi-linear shapes at current densities from $0.5 \mathrm{~A} / \mathrm{g}$ to $20 \mathrm{~A} / \mathrm{g}$. It also suggested that the as-obtained carbon samples possessed good electrochemical performances. Figure $8 \mathrm{~d}$ summarizes the gravimetric specific capacitances of a-CSHs, calculated from galvanostatic charge/discharge curves at a current density ranging from 0.5 to $20 \mathrm{~A} / \mathrm{g}$. The specific capacitance value of the a-CSH-700 sample was as high as $238 \mathrm{~F} / \mathrm{g}$ at a current density of $0.5 \mathrm{~A} / \mathrm{g}$, which was higher than those of a-CSH-800 (217 F/g) and a-CSH-600 (204 F/g). The capacitance was also as high as $200 \mathrm{~F} / \mathrm{g}$ for a-CSH-700 with an excellent capacitance retention of $92 \%$, indicating its outstanding rate capability. For a better comparison, Table 3 lists the specific capacitances of other biomass-derived porous carbons that were reported in the recent literature. Although the electrode of a-CSH-700 exhibited the best electrochemical performance, its specific area and surface functional groups were not the highest among all of the samples, meaning that there were synergistic effects. 

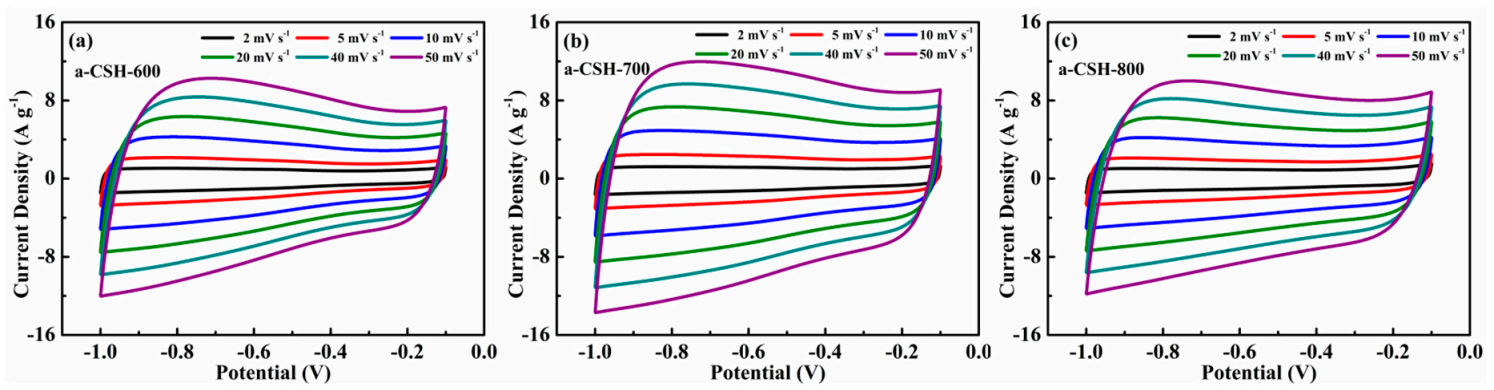

Figure 7. Electrochemical performance characteristics of a-CSHs measured in a three-electrode system in a $6 \mathrm{M} \mathrm{KOH}$ electrolyte: the cyclic voltammetry (CV) curves of (a) a-CSH-600, (b) a-CSH-700, and (c) a-CSH-800 at different scan rates.
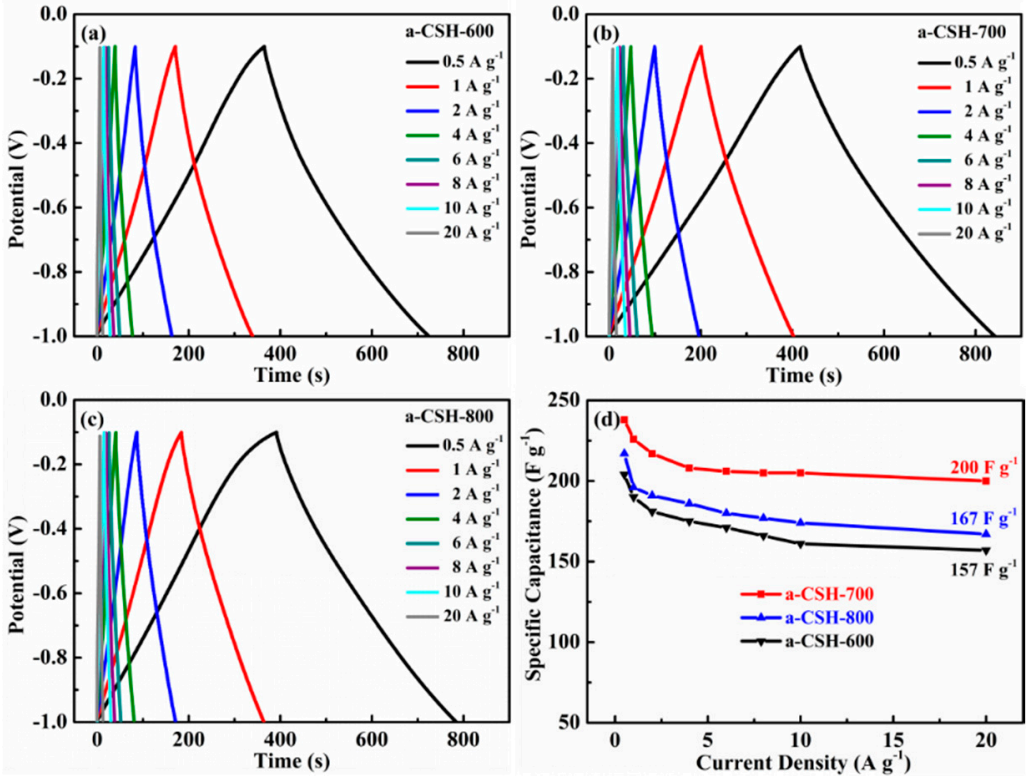

Figure 8. Electrochemical performance characteristics of a-CSHs measured in a three-electrode system in a $6 \mathrm{M} \mathrm{KOH}$ electrolyte: galvanostatic charge/discharge (GCD) curves of (a) a-CSH-600, (b) a-CSH-700, and (c) a-CSH-800 at different scan rates. (d) Specific capacitances at different current densities.

Table 3. Electrochemical performance of biomass derived porous carbons.

\begin{tabular}{cccccc}
\hline Materials & $\mathbf{S}_{\text {BET }}\left(\mathbf{m}^{\mathbf{2}} / \mathbf{g}\right)$ & $\mathbf{C}_{\mathbf{m}}(\mathbf{F} / \mathbf{g})$ & Current Density & Electrolyte & Ref. \\
\hline Broad beans & 655.4 & 129 & $10 \mathrm{~A} / \mathrm{g}$ & $6 \mathrm{M} \mathrm{KOH}$ & {$[52]$} \\
Banana peel & 1357.6 & 155 & $2.5 \mathrm{~A} / \mathrm{g}$ & $6 \mathrm{M} \mathrm{KOH}$ & {$[44]$} \\
Potato waste & 1052 & 192 & $10 \mathrm{~A} / \mathrm{g}$ & $2 \mathrm{M} \mathrm{KOH}$ & {$[53]$} \\
Banana peel & 1650 & 182 & $10 \mathrm{~A} / \mathrm{g}$ & $6 \mathrm{M} \mathrm{KOH}$ & {$[54]$} \\
Sugarcane bagasse & 1939.6 & 175 & $20 \mathrm{~A} / \mathrm{g}$ & $1 \mathrm{M} \mathrm{H}_{2} \mathrm{SO}_{4}$ & {$[55]$} \\
Pomelo & 974.6 & 176.4 & $20 \mathrm{~A} / \mathrm{g}$ & $2 \mathrm{M} \mathrm{KOH}$ & {$[56]$} \\
Chitin & 1600 & 196.2 & $20 \mathrm{~A} / \mathrm{g}$ & $6 \mathrm{M} \mathrm{KOH}$ & {$[57]$} \\
Cotton seed husk & 1694.1 & 200 & $20 \mathrm{~A} / \mathrm{g}$ & $6 \mathrm{M} \mathrm{KOH}$ & This work \\
\hline
\end{tabular}

The capacitive performance of a-CSH-700 was further evaluated by assembling it in a symmetric two-electrode cell in $6 \mathrm{M} \mathrm{KOH}$. Figure 9a shows the CV curves that were tested in different potential windows. It could be seen that there no obvious promotion of anodic current when the operating voltage was 1.2 V. The GCD curves (Figure 9b) had a symmetric triangular shape as the current density increased from $0.5 \mathrm{~A} / \mathrm{g}$ to $10 \mathrm{~A} / \mathrm{g}$, and there were no evident IR drops. The testing results also showed 
that it had a good capacitive performance. The specific capacitance for the entire electrochemical supercapacitor was estimated to be $52 \mathrm{~F} / \mathrm{g}$ at $0.5 \mathrm{~A} / \mathrm{g}$ with an energy density of $10.4 \mathrm{Wh} / \mathrm{kg}$ and power density $300 \mathrm{~W} / \mathrm{kg}$ (Figure $9 \mathrm{c}, \mathrm{e}$ ). Figure $9 \mathrm{~d}$ shows the cycling stability of the device at a higher current density of $10 \mathrm{~A} / \mathrm{g}$. It could be seen that the charge/discharge curves of the last two cycles were the same as the first two cycles (Figure 9f). Capacitance retention was also as high as $91 \%$ after 5000 cycles. These results revealed that the synthesized a-CSH-700 sample was a superior electrode material for high power and cost-effective supercapacitors.
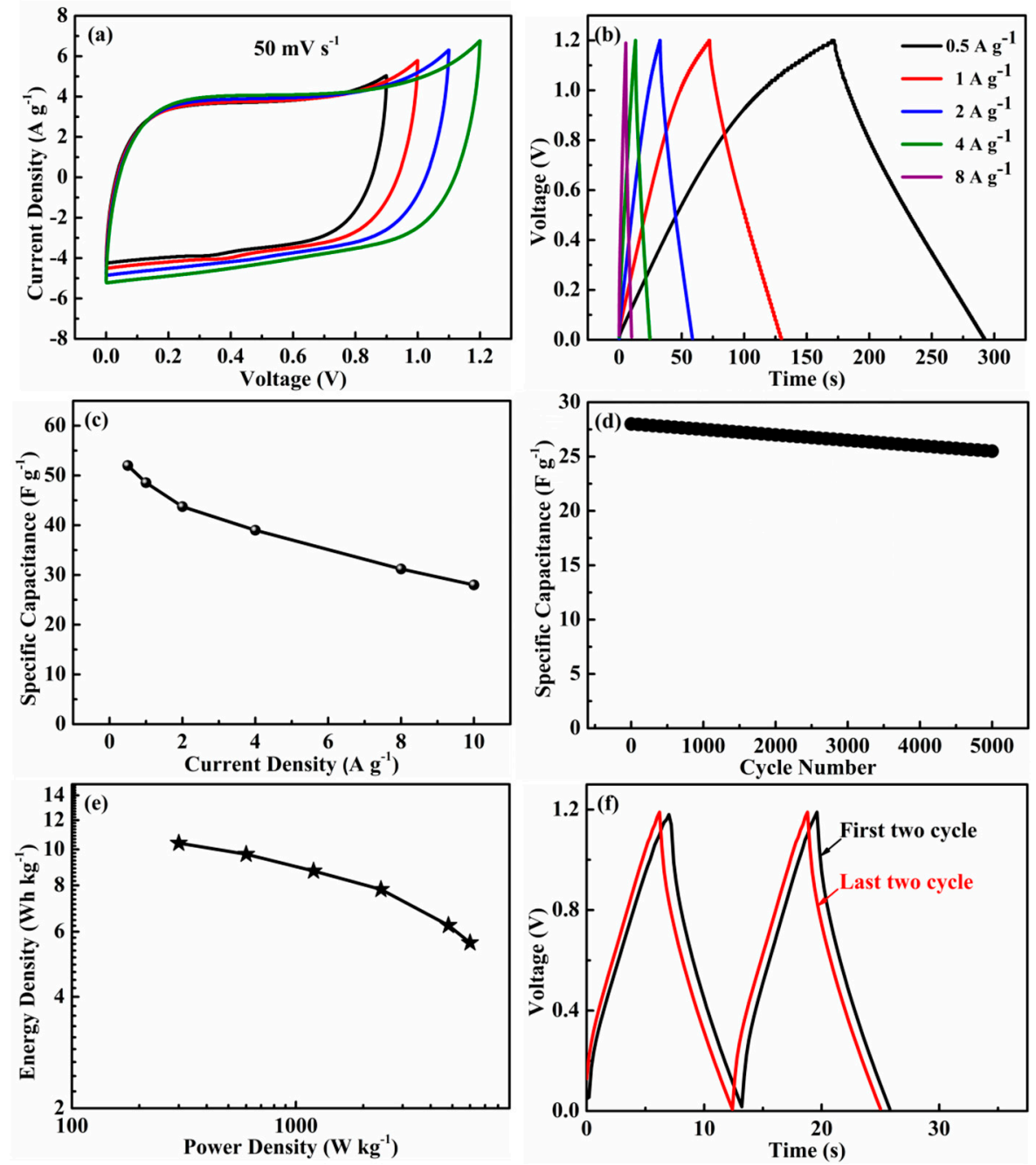

Figure 9. Electrochemical measurements of an as-assembled a-CSH-700//a-CSH-700 symmetric supercapacitor in a $6 \mathrm{M} \mathrm{KOH}$ electrolyte: (a) CV curves of the cell operated in different voltage windows at scan rate $50 \mathrm{mV} / \mathrm{s}$; (b) galvanostatic charge/discharge curves of the cell at various current densities; and (c) specific capacitances for the supercapacitor at different current densities. (d) Cycling stabilities of the devices at a current density of $10 \mathrm{~A} / \mathrm{g}$. (e) Ragone plot. (f) First two cycle charge-discharge and last two charge-dischage plots.

\section{Conclusions}

Nitrogen self-doped 3D honeycomb-like porous carbon was successfully prepared via one-step $\mathrm{KOH}$ activation (a-CSHs). When the carbonization temperature was adjusted, the obtained carbon materials showed high specific surface areas $\left(1257.8-2063.0 \mathrm{~m}^{2} / \mathrm{g}\right)$, abundant nitrogen contents (1.51-2.56 atom \%), and hierarchical pore structures. The a-CSH-700 based electrode delivered a high specific capacitance of $238 \mathrm{~F} / \mathrm{g}$ and $200 \mathrm{~F} / \mathrm{g}$ at current densities of $0.5 \mathrm{~A} / \mathrm{g}$ and $20 \mathrm{~A} / \mathrm{g}$, respectively, 
demonstrating a good capacitance retention of $84 \%$. Moreover, the assembled a-CSH-700 based symmetric supercapacitor also displayed a high specific capacitance of $52 \mathrm{~F} / \mathrm{g}$ at $0.5 \mathrm{~A} / \mathrm{g}$, with an energy density of $10.4 \mathrm{Wh} / \mathrm{kg}$ at $300 \mathrm{~W} / \mathrm{kg}$, and $91 \%$ capacitance retention after 5000 cycles at $10 \mathrm{~A} / \mathrm{g}$. This facile and cost-effective method for the preparation of 3D honeycomb-like porous carbon material from waste cottonseed husk was also renewable and easy for industrial production.

Author Contributions: F.Y. designed and administered the experiments. H.C. performed the experiments; H.C., G.W., L.C., and B.D. characterized the samples and collected the data; and F.Y., G.W., and B.D. gave technical support and conceptual advice. All of the authors contributed to the analysis and discussion of the data and to writing the manuscript.

Funding: This research was funded by the National Natural Science Foundation of China (Grant No. U1303291), the Program for Changjiang Scholars and Innovative Research Team in University (Grant No. IRT_15R46), and the Program of Science and Technology Innovation Team in Bingtuan (No. 2015BD003).

Conflicts of Interest: The authors declare no conflict of interest.

\section{References}

1. Zhang, L.L.; Zhao, X.S. Carbon-based materials as supercapacitor electrodes. Chem. Soc. Rev. 2009, 38, 2520-2532. [CrossRef] [PubMed]

2. Miller, J.R.; Simon, P. Electrochemical capacitors for energy management. Science 2008, 321, $651-652$. [CrossRef] [PubMed]

3. Qin, T.; Wan, Z.; Wang, Z.; Wen, Y.; Liu, M.; Peng, S.; He, D.; Hou, J.; Huang, F.; Cao, G. 3D flexible $\mathrm{O} / \mathrm{N}$ co-doped graphene foams for supercapacitor electrodes with high volumetric and areal capacitances. J. Power Sources 2016, 336, 455-464. [CrossRef]

4. Zhao, G.; Chen, C.; Yu, D.; Sun, L.; Yang, C.; Zhang, H.; Sun, Y.; Besenbacher, F.; Yu, M. One-step production of O-N-S co-doped three-dimensional hierarchical porous carbons for high-performance supercapacitors. Nano Energy 2018, 47, 547-555. [CrossRef]

5. Qin, T.; Peng, S.; Hao, J.; Wen, Y.; Wang, Z.; Wang, X.; He, D.; Zhang, J.; Hou, J.; Cao, G. Flexible and wearable all-solid-state supercapacitors with ultrahigh energy density based on a carbon fiber fabric electrode. Adv. Energy Mater. 2017, 7. [CrossRef]

6. Wen, Y.; Peng, S.; Wang, Z.; Hao, J.; Qin, T.; Lu, S.; Zhang, J.; He, D.; Fan, X.; Cao, G. Facile synthesis of ultrathin $\mathrm{NiCo}_{2} \mathrm{~S}_{4}$ nano-petals inspired by blooming buds for high-performance supercapacitors. J. Mater. Chem. A 2017, 5, 7144-7152. [CrossRef]

7. Liu, L.; Niu, Z.; Chen, J. Unconventional supercapacitors from nanocarbon-based electrode materials to device configurations. Chem. Soc. Rev. 2016, 45, 4340-4363. [CrossRef] [PubMed]

8. Wang, J.; Kaskel, S. Koh activation of carbon-based materials for energy storage. J. Mater. Chem. 2012, 22, 23710-23725. [CrossRef]

9. Zhang, Y.; Liu, X.; Wang, S.; Li, L.; Dou, S. Bio-nanotechnology in high-performance supercapacitors. Adv. Energy Mater. 2017, 7. [CrossRef]

10. Yan, J.; Wang, Q.; Wei, T.; Fan, Z. Recent advances in design and fabrication of electrochemical supercapacitors with high energy densities. Adv. Energy Mater. 2014, 4. [CrossRef]

11. Liu, L.; Niu, Z.; Chen, J. Flexible supercapacitors based on carbon nanotubes. Chinese Chem. Lett. 2018, 4, 571-581. [CrossRef]

12. Hou, J.; Cao, C.; Idrees, F.; Ma, X. Hierarchical porous nitrogen-doped carbon nanosheets derived from silk for ultrahigh-capacity battery anodes and supercapacitors. ACS Nano 2015, 9, 2556-2564. [CrossRef] [PubMed]

13. Raymundo-Piñero, E.; Kierzek, K.; Machnikowski, J.; Béguin, F. Relationship between the nanoporous texture of activated carbons and their capacitance properties in different electrolytes. Carbon 2006, 44, 2498-2507. [CrossRef]

14. Chen, T.; Dai, L. Carbon nanomaterials for high-performance supercapacitors. Mater. Today 2013, 16, $272-280$. [CrossRef]

15. Wu, X.; Jiang, L.; Long, C.; Fan, Z. From flour to honeycomb-like carbon foam: Carbon makes room for high energy density supercapacitors. Nano Energy 2015, 13, 527-536. [CrossRef] 
16. Liu, Y.; Xiao, Z.; Liu, Y.; Fan, L.Z. Biowaste-derived 3d honeycomb-like porous carbon with binary-heteroatom doping for high-performance flexible solid-state supercapacitors. J. Mater. Chem. A 2017, 6, 160-166. [CrossRef]

17. Salanne, M.; Rotenberg, B.; Naoi, K.; Kaneko, K.; Taberna, P.L.; Grey, C.P.; Dunn, B.; Simon, P. Efficient storage mechanisms for building better supercapacitors. Nat. Energy 2017, 1, 16070. [CrossRef]

18. Forse, A.C.; Merlet, C.; Griffin, J.M.; Grey, C.P. Newperspectives on the charging mechanisms of supercapacitors. J. Am. Chem. Soc. 2016, 138, 5731-5744. [CrossRef] [PubMed]

19. Yu, Z.; Tetard, L.; Zhai, L.; Thomas, J. Supercapacitor electrode materials: Nanostructures from 0 to 3 dimensions. Energy Environ. Sci. 2015, 8, 702-730. [CrossRef]

20. Dutta, S.; Bhaumik, A.; Wu, C.W. Hierarchically porous carbon derived from polymers and biomass: Effect of interconnected pores on energy applications. Energy Environ. Sci. 2014, 7, 3574-3592. [CrossRef]

21. Wang, X.; Zhang, Y.; Zhi, C.; Wang, X.; Tang, D.; Xu, Y.; Weng, Q.; Jiang, X.; Mitome, M.; Golberg, D. Three-dimensional strutted graphene grown by substrate-free sugar blowing for high-power-density supercapacitors. Nat. Commun. 2013, 4, 2905. [CrossRef] [PubMed]

22. Ghimire, P.; Gunathilake, C.; Wickramaratne, N.P.; Jaroniec, M. Tetraethyl orthosilicate-assisted synthesis of nitrogen-containing porous carbon spheres. Carbon 2017, 121, 408-417. [CrossRef]

23. Li, B.; Dai, F.; Xiao, Q.; Yang, L.; Shen, J.; Zhang, C.; Cai, M. Nitrogen-doped activated carbon for high energy hybrid supercapacitor. Energy Environ. Sci. 2015, 9, 102-106. [CrossRef]

24. Yang, W.; Hou, L.; Xu, X.; Li, Z.; Ma, X.; Yang, F.; Li, Y. Carbon nitride template-directed fabrication of nitrogen-rich porous graphene-like carbon for high performance supercapacitors. Carbon 2018. [CrossRef]

25. Wang, C.; Wang, F.; Liu, Z.; Zhao, Y.; Liu, Y.; Yue, Q.; Zhu, H.; Deng, Y.; Wu, Y.; Zhao, D. N-doped carbon hollow microspheres for metal-free quasi-solid-state full sodium-ion capacitors. Nano Energy 2017, 41, 674-680. [CrossRef]

26. Wei, L.; Sevilla, M.; Fuertes, A.B.; Mokaya, R.; Yushin, G. Hydrothermal carbonization of abundant renewable natural organic chemicals for high-performance supercapacitor electrodes. Adv. Energy Mater. 2011, 1, 356-361. [CrossRef]

27. Wei, X.; Zou, H.; Gao, S. Chemical crosslinking engineered nitrogen-doped carbon aerogels from polyaniline-boric-acid-polyvinyl-alcohol gels for high-performance electrochemical capacitors. Carbon 2017, 123, 471-480. [CrossRef]

28. Wang, C.; Zhou, Y.; Sun, L.; Wan, P.; Zhang, X.; Qiu, J. Sustainable synthesis of phosphorus- and nitrogen-co-doped porous carbons with tunable surface properties for supercapacitors. J. Power Sources 2013, 239, 81-88. [CrossRef]

29. Jeong, H.M.; Lee, J.W.; Shin, W.H.; Choi, Y.J.; Shin, H.J.; Kang, J.K.; Choi, J.W. Nitrogen-doped graphene for high-performance ultracapacitors and the importance of nitrogen-doped sites at basal planes. Nano Lett. 2011, 11, 2472-2477. [CrossRef] [PubMed]

30. Su, F.; Poh, C.K.; Chen, J.S.; Xu, G.; Wang, D.; Li, Q.; Lin, J.; Lou, X.W. Nitrogen-containing microporous carbon nanospheres with improved capacitive properties. Energy Environ. Sci. 2011, 4, 717-724. [CrossRef]

31. Yan, J.; Wei, T.; Qiao, W.; Fan, Z.; Zhang, L.; Li, T.; Zhao, Q. A high-performance carbon derived from polyaniline for supercapacitors. Electrochem. Commun. 2010, 12, 1279-1282. [CrossRef]

32. Ornelas, O.; Sieben, J.M.; Ruizrosas, R.; Morallón, E.; Cazorlaamorós, D.; Geng, J.; Soin, N.; Siores, E.; Johnson, B.F. On the origin of the high capacitance of nitrogen-containing carbon nanotubes in acidic and alkaline electrolytes. Chem. Commun. 2014, 50, 11343-11346. [CrossRef] [PubMed]

33. Zou, K.; Deng, Y.; Chen, J.; Qian, Y.; Yang, Y.; Li, Y.; Chen, G. Hierarchically porous nitrogen-doped carbon derived from the activation of agriculture waste by potassium hydroxide and urea for high-performance supercapacitors. J. Power Sources 2018, 378, 579-588. [CrossRef]

34. Tian, W.; Zhang, H.; Sun, H.; Tadé, M.O.; Wang, S. Template-free synthesis of n-doped carbon with pillared-layered pores as bifunctional materials for supercapacitor and environmental applications. Carbon 2017, 118, 98-105. [CrossRef]

35. Kim, N.D.; Kim, W.; Ji, B.J.; Oh, S.; Kim, P.; Kim, Y.; Yi, J. Electrochemical capacitor performance of n-doped mesoporous carbons prepared by ammoxidation. J. Power Sources 2008, 180, 671-675. [CrossRef]

36. Chen, M.; Kang, X.; Dou, J.; Gao, B.; Han, Y.; Xu, G.; Liu, Z.; Zhang, L. Preparation of activated carbon from cotton stalk and its application in supercapacitor. J. Solid State Electrochem. 2013, 17, 1005-1012. [CrossRef] 
37. Zhang, Q.; Han, K.; Li, S.; Li, M.; Li, J.; Ren, K. Synthesis of garlic skin-derived 3D hierarchical porous carbon for high-performance supercapacitors. Nanoscale 2018, 10, 2427. [CrossRef] [PubMed]

38. Qian, W.; Sun, F.; Xu, Y.; Qiu, L.; Liu, C.; Wang, S.; Yan, F. Human hair-derived carbon flakes for electrochemical supercapacitors. Energy Environ. Sci. 2013, 7, 379-386. [CrossRef]

39. Gao, S.; Geng, K.; Liu, H.; Wei, X.; Zhang, M.; Wang, P.; Wang, J. Transforming organic-rich amaranthus waste into nitrogen-doped carbon with superior performance of oxygen reduction reaction. Energy Environ. Sci. 2014, 8, 221-229. [CrossRef]

40. Chen, H.; Guo, Y.C.; Wang, F.; Wang, G.; Qi, P.R.; Guo, X.H.; Dai, B.; Yu, F. An activated carbon derived from tobacco waste for use as a supercapacitor electrode material. New Carbon Mater. 2017, 32, 592-599. [CrossRef]

41. Kai, W.; Ning, Z.; Lei, S.; Rui, Y.; Tian, X.; Wang, J.; Yan, S.; Xu, D.; Guo, Q.; Lang, L. Promising biomass-based activated carbons derived from willow catkins for high performance supercapacitors. Electrochim. Acta 2015, 166, 1-11.

42. Xie, L.; Sun, G.; Su, F.; Guo, X.; Kong, Q.Q.; Li, X.M.; Huang, X.; Wan, L.; Song, W.; Li, K. Hierarchical porous carbon microtubes derived from willow catkins for supercapacitor application. J. Mater. Chem. A 2015, 4, 1637-1646. [CrossRef]

43. Kim, N.D.; Buchholz, D.B.; Casillas, G.; José-Yacaman, M.; Chang, R.P.H. Hierarchical design for fabricating cost-effective high performance supercapacitors. Adv. Funct. Mater. 2014, 24, 4186-4194. [CrossRef]

44. Liu, B.; Zhang, L.; Qi, P.; Zhu, M.; Wang, G.; Ma, Y.; Guo, X.; Chen, H.; Zhang, B.; Zhao, Z. Nitrogen-doped banana peel-derived porous carbon foam as binder-free electrode for supercapacitors. Nanomaterials 2016, 6, 18. [CrossRef] [PubMed]

45. Huang, Y.; Peng, L.; Liu, Y.; Zhao, G.; Chen, J.Y.; Yu, G. Biobased nano porous active carbon fibers for high-performance supercapacitors. ACS Appl. Mater. Interfaces 2016, 8, 15205-15215. [CrossRef] [PubMed]

46. Wang, Y.; Zhu, M.; Wang, G.; Dai, B.; Yu, F.; Tian, Z.; Guo, X. Enhanced oxygen reduction reaction by in situ anchoring $\mathrm{Fe}_{2} \mathrm{~N}$ nanoparticles on nitrogen-doped pomelo peel-derived carbon. Nanomaterials 2017, 7, 404. [CrossRef] [PubMed]

47. Shi, L.; Wu, T.; Wang, Y.; Zhang, J.; Wang, G.; Zhang, J.; Dai, B.; Yu, F. Nitrogen-doped carbon nanoparticles for oxygen reduction prepared via a crushing method involving a high shear mixer. Materials 2017, 10, 1030. [CrossRef] [PubMed]

48. Wang, Y.; Zhu, M.; Li, Y.; Zhang, M.; Xue, X.; Shi, Y.; Dai, B.; Guo, X.; Yu, F. Heteroatom-doped porous carbon from methyl orange dye wastewater for oxygen reduction. Green Energy Environ. 2017. [CrossRef]

49. Wang, Y.; Yu, F.; Zhu, M.; Ma, C.; Zhao, D.; Wang, C.; Zhou, A.; Dai, B.; Ji, J.; Guo, X. N-doping of plasma exfoliated graphene oxide via dielectric barrier discharge plasma treatment for oxygen reduction reaction. J. Mater. Chem. A 2018, 6, 2011-2017. [CrossRef]

50. Ania, C.O.; Khomenko, V.; Raymundo-Piñero, E.; Parra, J.B.; Béguin, F. The large electrochemical capacitance of microporous doped carbon obtained by using a zeolite template. Adv. Funct. Mater. 2007, 17, 1828-1836. [CrossRef]

51. Wu, J.; Zhang, D.; Wang, Y.; Hou, B. Electrocatalytic activity of nitrogen-doped graphene synthesized via a one-pot hydrothermal process towards oxygen reduction reaction. J. Power Sources 2013, 227, 185-190. [CrossRef]

52. Xu, G.Y.; Han, J.P.; Bing, D.; Ping, N.; Jin, P.; Hui, D.; Li, H.S.; Zhang, X.G. Biomass-derived porous carbon materials with sulfur and nitrogen dual-doping for energy storage. Green Chem. 2015, 17, 1668-1674. [CrossRef]

53. Ma, G.; Yang, Q.; Sun, K.; Peng, H.; Ran, F.; Zhao, X.; Lei, Z. Nitrogen-doped porous carbon derived from biomass waste for high-performance supercapacitor. Bioresour. Technol. 2015, 197, 137-142. [CrossRef] [PubMed]

54. Lv, Y.; Gan, L.; Liu, M.; Xiong, W.; Xu, Z.; Zhu, D.; Wright, D.S. A self-template synthesis of hierarchical porous carbon foams based on banana peel for supercapacitor electrodes. J. Power Sources 2012, 209, $152-157$. [CrossRef]

55. Wang, B.; Wang, Y.; Peng, Y.; Wang, X.; Wang, J.; Zhao, J. 3-dimensional interconnected framework of n-doped porous carbon based on sugarcane bagasse for application in supercapacitors and lithium ion batteries. J. Power Sources 2018, 390, 186-196. [CrossRef] 
56. Peng, H.; Ma, G.; Sun, K.; Zhang, Z.; Yang, Q.; Lei, Z. Nitrogen-doped interconnected carbon nanosheets from pomelo mesocarps for high performance supercapacitors. Electrochim. Acta 2016, 190, 862-871. [CrossRef]

57. Jie, Z.; Li, B.; Wu, S.; Wei, Y.; Hui, W. Chitin based heteroatom-doped porous carbon as electrode materials for supercapacitors. Carbohydr. Polym. 2017, 173, 321-329. 